\title{
Origin of fecal contamination in waters from contrasted areas: Stanols as Microbial Source Tracking markers
}

\author{
M. Derrien ${ }^{a}$, E. Jardé ${ }^{a},{ }^{\star}$, G. Gruau ${ }^{a}$, A.M. Pourcher ${ }^{b}$, M. Gourmelon $^{c}$, A. Jadas-Hécart ${ }^{d}$, A.C. Pierson \\ Wickmann ${ }^{\mathrm{a}}$
}

\author{
${ }^{a}$ Géosciences Rennes, UMR CNRS-Université de Rennes I, Campus de Beaulieu, bâtiment 15 bureau 306/2, \\ 35042 Rennes Cedex, France \\ ${ }^{\mathrm{b}}$ Cemagref, Rennes, France \\ ${ }^{c}$ Ifremer, EMP, Laboratoire de Microbiologie, Plouzané, France \\ ' Université d'Angers, France
}

*: Corresponding author : E. Jardé, Tel.: +33 223235 620; fax: +33 223236 090, , email address : emilie.jarde@univ-rennes1.fr

\begin{abstract}
:
Improving the microbiological quality of coastal and river waters relies on the development of reliable markers that are capable of determining sources of fecal pollution. Recently, a principal component analysis (PCA) method based on six stanol compounds (i.e. $5 \beta$-cholestan-3 $\beta$-ol (coprostanol), $5 \beta$ -

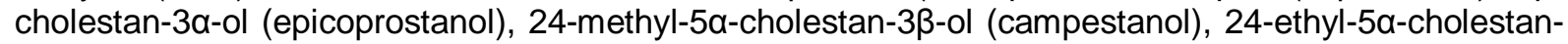

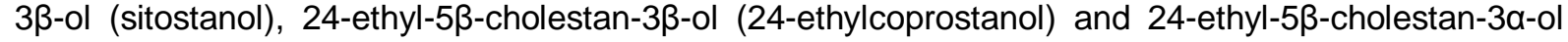
(24-ethylepicoprostanol)) was shown to be suitable for distinguishing between porcine and bovine feces. In this study, we tested if this PCA method, using the above six stanols, could be used as a tool in "Microbial Source Tracking (MST)" methods in water from areas of intensive agriculture where diffuse fecal contamination is often marked by the co-existence of human and animal sources. In particular, well-defined and stable clusters were found in PCA score plots clustering samples of "pure" human, bovine and porcine feces along with runoff and diluted waters in which the source of contamination is known. A good consistency was also observed between the source assignments made by the 6-stanol-based PCA method and the microbial markers for river waters contaminated by fecal matter of unknown origin. More generally, the tests conducted in this study argue for the addition of the PCA method based on six stanols in the MST toolbox to help identify fecal contamination sources. The data presented in this study show that this addition would improve the determination of fecal contamination sources when the contamination levels are low to moderate.
\end{abstract}




\section{Graphical abstract}

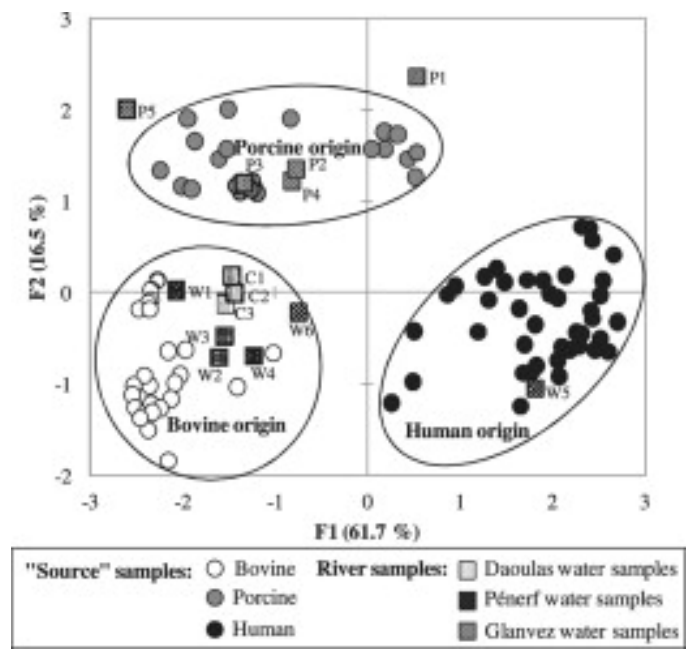

\section{Highlights}

Distinction between bovine, porcine and human sources in pure samples. Transfer of the sourcespecific stanol fingerprint during runoff and dilution experimentations. Application and validation of the PCA method to River Basins contaminated with animal and human contamination.

Keywords: Stanols; Microbial Source Tracking; Principal component analysis; Microbial markers 


\section{Introduction}

Fecal contamination from human and animal waste not only contributes to the degradation of aquatic systems but also affects water quality, thereby posing a serious threat to human health from exposure to pathogenic bacteria, viruses, and protozoa (Sinton et al., 1998; Asperen et al., 1998). Management plans are required in order to limit these risks and improve water quality, including tools capable of identifying fecal contamination sources need to be developed. This need is particularly important in Europe where the revised Bathing Water European Directive (2006/7/EC) recently introduced more stringent microbial concentration limits together with the need to establish bathing water profiles in which the animal or human origin of the fecal contamination must be determined, a requirement that is also included in the revised European Shellfish Directive (Regulation (EC) 854/2004). Yet, the fecal indicator bacteria (FIB) used in the regulations to determine fecal contamination are not source specific as they are found in the feces of most warm-blooded animals (e.g. birds, mammals) (Sinton et al., 1998; Scott et al., 2002).

During the past decade, several microbial and chemical markers associated with human and animal feces, or their related effluents, have been proposed as methods to identify fecal contamination sources (Simpson et al., 2002; Cimenti et al., 2007). These methods, collectively referred as to "Microbial Source Tracking" (MST) methods, were developed to discriminate between human and non-human sources of fecal contamination as well as between different animal species. For example, chemical makers such as stanols, bile acids, caffeine and synthetic compounds released into urban wastewater have been used to distinguish between human and animal contamination (Leeming et al., 1996; Bull et al., 2002; Shah et al., 2007; Tyagi et al., 2009). Microbial markers such as bacteria, Archeabacteria and viruses have also been tested (Bernhard and Field, 2000; Ufnar et al., 2007) and used in a few cases in association with the chemical MST toolbox (Blanch et al., 2006; Gourmelon et al., 2010).

A particularly interesting method is the use of chemical markers such as stanols. Animal and human feces contain a considerable amount of stanols with different relative proportions, suggesting that particular ratios could be used as fecal contamination source markers. Within the last twenty or so years, six such ratios were developed and used for this purpose (Grimalt et al., 1990; Fattore et al., 1996; Leeming et al., 1996; Bull et al., 2002; Jardé et al., 2007a, 2007b; Shah et al., 2007; Gourmelon et al., 2010). However their use has very recently been questioned following results which showed that the values of certain animal sources (namely porcine and bovine) overlap (Derrien et al., 2011). Does this mean that stanols can no longer be used to track sources of fecal contamination? It has been shown that a PCA method based on six stanol compounds (i.e. coprostanol, epicoprostanol, campestanol, sitostanol, 24-ethylcoprostanol and 24-ethylepicoprostanol) can be used to circumvent the above mentioned problem of loss of ratio specificity (Derrien et al., 2011). However, so far, this method has only been tested on porcine and bovine sources and thus its ability to discriminate between animal and human sources still needs to be established. The ability of the PCA method based on six stanols to discriminate between porcine and bovine sources after the waste has been transported from soil to water also needs to be tested. Animal feces are commonly applied to agricultural soils and during rainfall events, water can become contaminated due to runoff. The following question therefore arises: could the transport of feces by runoff lead to a loss of specificity of the PCA method based on six stanols. Finally, this method needs to be compared with other MST methods. Indeed, no single source tracking microbial or chemical method appears sufficiently discriminatory to identify the origin of fecal contamination in water (Blanch et al., 2006; Field and Samadpour, 2007), making it very important to compare the methods against each other before validating the former method as reliable contamination source tracking methods.

This study aims to (i) further develop a chemometric analysis of the stanol part of the steroid fingerprint in order to discriminate human from bovine and porcine fecal 
contamination sources, and (ii) validate this tool in natural waters impacted by single or multiple contamination sources in comparison with microbial and other chemical markers.

\section{Materials and methods}

\subsection{Type and origin of samples}

Given the problems outlined in introduction, a three-step study was conducted. In the first step, the samples previously used by Derrien et al. (2011) to set up the PCA method based on six stanols were pooled and treated together with a series of influent/effluent samples from urban wastewater treatment plants (WWTP) to verify the ability of the method to discriminate between "pure" porcine, bovine and human fecal sources. In a second step, results obtained earlier on i) runoff water from soil amended with porcine and bovine feces (Jaffrezic et al., 2011) and ii) WWTP effluent samples diluted in fresh and sea water (Solecki et al., 2011; Jeanneau et al., 2011) were added to the "pure" fecal source database and treated along with this database to test if the capacity of the PCA method based on six stanols is still applicable when dilution and transport of feces by runoff occur. Finally, in a third step, the method was applied to water samples from three coastal river basins (the Daoulas, Glanvez and Pénerf River Basins) undergoing recurrent animal and/or human fecal contamination, and its results were compared with information provided by microbial and other chemical tracers (Gourmelon et al., 2010) regarding the source(s) of the fecal contamination (Table 1).

All samples were collected in Brittany and Maine-et-Loire (both regions are located in Western France). Brittany, which generates from 8 to 10 million tons of pig slurry and 20 million tons of bovine manure per year, represents an ideal target for developing, testing and comparing MST methods.

\subsubsection{Concentrated and diluted "pure" animal source samples}

The "pure" animal source samples (bovine and porcine) comprise published stanol results from i) nineteen samples of bovine feces and sixteen samples of porcine feces (Derrien et al., 2011) and ii) twelve runoff water collected during rainfall simulations performed on an agricultural experimental plot previously amended with bovine or porcine from Jaffrézic et al. (2011).

\subsubsection{Concentrated and diluted "pure" human source samples}

Thirty-five samples of WWTP influents $(n=17)$, effluents $(n=16)$ and sludge $(n=2)$ coming from 20 different WWTP were also included in the present study. Among these 35 samples, four correspond to samples that were previously investigated by Gourmelon et al. (2010); the remaining 31 samples are new samples and their stanol profiles were determined in the present study.

Six diluted WWTP samples were also included here. Untreated WWTP influent (5L) was diluted in 90L of unfiltered water (sea or fresh water) at a 1:18 dilution ratio. This dilution ratio corresponds to a low hydraulic impact of WWTP effluent on a receiving body (Figuet et al., 2000). The experimental design is fully described in Jeanneau et al. (2012) who also provided the stanols analyses of these samples.

\subsubsection{Samples from the Daoulas, Glanvez and Pénerf River Basins}

The Daoulas River is a river located in Western Brittany that flows through an agricultural area associated with intensive bovine grazing. Stanol and microbial marker data from the three samples come from the study of Gourmelon et al. (2010) (samples C1-C3). 
The Glanvez Catchment is located in Western Brittany. Five water samples were collected in March 2011 downstream of an accidental spillage from a pig manure tank due to a pipe

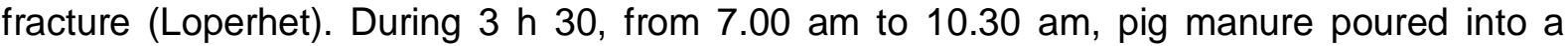
pond, then into a watercourse that flowed into the Glanvez river, $50 \mathrm{~m}$ downstream and the river reaches the sea at Penfoul, $3 \mathrm{~km}$ downstream the farm. After $2 \mathrm{~h} 30$ spillage $(9.30 \mathrm{am})$, one sample was collected at the point where the watercourse from the tank joined the Glanvez river (P1) and a second sample was collected at the Penfoul site (P2). The day after the spillage $(8.00 \mathrm{am})$, two samples were collected from the watercourse connected to the pond, 40 m downstream the farm (P3 and P4), and one where the watercourse from the tank joined the Glanvez river (P5).

The Pénerf River Basin is a small $\left(136 \mathrm{~km}^{2}\right)$ coastal river basin located in SW Brittany, near the city of Vannes. The estuarine portion of the basin near Damgan and La Tour du Parc is the site of large-scale shellfish activity, with 53 shellfish farms spread over 235 ha. The two main rivers draining the basin (the Drayac and Surzur Rivers) were sampled. Microbial contamination is recurrent in these rivers, with temporary high concentration of $\mathrm{E}$. coli $(1 \times 105 \mathrm{cells} / 100 \mathrm{~mL}$ in the rivers, data from 2008-2009). Two sources are believed to be involved in this contamination, including i) the dairy farms occupying the river basin and ii) a municipal WWTP that discharge wastewater into the Surzur Rivers. The sampling strategy was realized with two samples (W5 and W6) downstream of the municipal WWTP (20 meters and $2 \mathrm{~km}$ downstream, respectively), and four (W1, W2, W3 and W4) collected in intensive bovine grazing areas. All samples were collected on the same day (May 25, 2010).

\subsection{Analytical methods}

\subsubsection{Microbial markers}

The enumeration of E. coli was performed using the culture methods described previously by Solecki et al. (2011). The detection limit was 1 colony forming unit (CFU) per $100 \mathrm{~mL}$.

Along with E. coli, three microbial markers were investigated in this study. These include two host-specific Bacteriodales markers - i) HF 183, which is known to specifically trace human contamination (Seurinck et al., 2005), and ii) Rum-2-Bac, which traces bovine contamination (Mieszkin et al., 2010) - and one pig-specific bacterial marker Lactobacillus amylovorus (L. amy) (Marti et al., 2010). The quantification of HF183, Rum-2-bac and L. amy were performed by real-time PCR using the methods described by Gourmelon et al. (2010) and Mieszkin et al. (2010). The quantification limit (QL) was set at five copies per PCR well in triplicate. The equivalent QL concentrations ranged from $2.5 \times 10^{2}$ to $5 \times 10^{3} \mathrm{CFU}$ equivalents $/ 100 \mathrm{~mL}$ water, depending on the water volume filtered and the DNA extract dilution used for the PCR.

\subsubsection{Chemical markers}

The chemical methods have been described in details in the Supporting Information file. Stanols were analyzed and quantified as their trimethylsilyl derivatives by GC-MS as described by in Derrien et al. (2011) and Jeanneau et al. (2011). The limit of quantification of the stanols was $0.01 \mu \mathrm{g} / \mathrm{L}$ in the water samples. Caffeine and tri(2-chloroethyl)phosphate (TCEP) - were analyzed in the Pénerf samples along with the stanols and microbial markers, as described in Gourmelon et al. (2010). The limit of quantification of these two compounds was $0.04 \mu \mathrm{g} / \mathrm{L}$ in the water samples.

\subsection{Statistical analysis}

The statistical methods have been described in details in the Supporting Information file. Briefly, in this study, we used the PCA method based on six stanols (i.e., coprostanol, 
epicoprostanol, 24-ethylcoprostanol, 24-ethylepicoprostanl, campestanol, and sitostanol) previously set up by Derrien et al., 2011. The original data were not normalized because the data have the same order of magnitude (i.e. relative abundances, in percentages, of the stanols quantified) and the not detected (ND) data were replaced by zero.

The PCA and relative statistical tests were performed with XLSTAT (Addinsoft, 2010), using nonparametric tests for small samples of unknown distribution (Mann-Whitney).

\section{Results}

\subsection{Statistical analysis of concentrated and diluted "pure" source stanol signatures}

Figure 1 displays the PCA analysis performed using the 35 porcine and bovine samples previously used by Derrien et al. (2011) to define these two fecal sources, along with the 35 WWTP samples used in this study. The first two components of this PCA explained $77.2 \%$ of the total variance. The figure illustrates a clear separation between the three sample types, confirming that the PCA method based on six stanols used by Derrien et al. (2011) to distinguish bovine feces from porcine feces is also able to discriminate human feces from bovine and porcine feces. The PCA analysis reveals that coprostanol discriminates the substanol series of human samples, while the bovine and porcine samples are discriminated mainly by sitostanol and 24-ethylepicoprostanol, respectively (Table A.1).

To test if the PCA method based on six stanols is still valid if the stanol profiles of the fecal sources are modified after their introduction and further transfer into the environment, the samples from the runoff and dilution experiments were added as supplementary individuals in the PCA. Figure 1 shows that the differences observed between the concentrated "pure" source samples and both the runoff and diluted samples remain essentially the same. It is particularly notable that the fresh water and sea water samples spiked with WWTP influent waters lie within the "human" group defined by the concentrated WWTP samples alone and the runoff samples from plots amended with porcine manure are found within the "porcine" group defined by the porcine manure samples. In fact, the only significant difference occurs with the bovine samples for which the runoff samples from the experimental plot amended with bovine manure lie significantly above the "bovine" group defined by the bovine manure samples. It is due to a decrease of the relative proportion of 24-ethylepicoprostanol, which is basically the stanol that defines the bovine cluster.

A discriminant analysis was used to determine if the groups defined by the PCA differ with respect to the variable means and, by using the variables defining each group, if the supplementary individuals are true members of the corresponding groups. The discriminant analysis results showed a $100 \%$ reclassification of all the individuals. As all 88 samples were found to be correctly classified, a new PCA was performed using the entire sample suite (concentrated "pure" source samples + runoff and diluted samples) as primary individuals. The results of this new PCA are given in Table A.2 and are shown in Figure 2. The first two components of the new PCA explained $78.2 \%$ of the total variance. The main contributive variables on axes F1 and F2 are the same as those controlling axes F1 and F2 in the PCA that analyzed the "pure" source samples only. As indicated in Figure 2, the new PCA still separates the "human", "bovine" and "porcine" groups while taking the possible fractionation effects induced by the dilution and transport of the stanols into account.

\subsection{Comparison with river samples}

River samples from the Daoulas, Glanvez and Pénerf River Basins were pooled with the above sample suite and treated as supplementary individuals in the PCA (Figure 2). As can be seen in the figure 2, all of the samples of Glanvez catchment lie inside the "porcine" group 
and all samples of Daoulas and Pénerf River Basins except W5 lie inside the "bovine" group. W5 falls within the "human" group.

The PCA results can be compared with microbial data and the caffeine and TCEP results. The highest E. coli concentration was recorded in sample W5 from the Pénerf River Basin: $1.4 \times 10^{5} \mathrm{CFU} / 100 \mathrm{~mL}$. Concentrations in the other samples from this basin were two orders of magnitude lower: between 1.4 and $6.1 \times 10^{3} \mathrm{CFU} / 100 \mathrm{~mL}$. Concentrations in the samples from the Daoulas River Basin were intermediate: between 1.5 and $1.9 \times 10^{4} \mathrm{CFU} / 100 \mathrm{~mL}$ (Gourmelon et al., 2010). And concentrations in the samples from Glanvez River Basin were between $3.3 \times 10^{2}$ and $9.2 \times 10^{3} \mathrm{CFU} / 100 \mathrm{~mL}$.

As regards the microbial marker results (Table 2), the porcine-specific $L \cdot$ amylovorus marker was detected in all samples from Glanvez catchment. The human-specific marker HF 183 was quantified only in sample W5. However, the concentration in this sample was quite high $\left(7.3 \times 10^{5}\right.$ gene copies $\left./ 100 \mathrm{~mL}\right)$, which is close to the concentrations found in WWTP effluents (Gourmelon et al., 2010). With respect to the bovine specific marker Rum-2, concentrations were high in the three samples from the Daoulas River and in one sample (W2) from the Pénerf River Basin (between $1.7 \times 10^{5}$ and $5.9 \times 10^{5}$ gene copies $/ 100 \mathrm{~mL}$ ).

TCEP concentrations were below the quantification limit in all the samples except in samples W5 and W6 from the Pénerf River Basin. However, the concentrations in these two samples were quite different: the concentration in the W5 sample $(0.29 \mu \mathrm{g} / \mathrm{L})$ was $>5$ times higher than that of sample W6 $(0.05 \mu \mathrm{g} / \mathrm{L})$. For caffeine, the concentration was very high in the W5 sample from the Pénerf River Basin $(12.40 \mu \mathrm{g} / \mathrm{L})$. Some caffeine was also quantified in samples W2, W3, W4 and W6 from this basin at much lower concentration levels (between 0.08 and $0.22 \mu \mathrm{g} / \mathrm{L})$.

\section{Discussion}

\subsection{Ability of the PCA method do discriminate concentrated and diluted "pure" source samples.}

An efficient MST toolbox is critical for identifying the origin of fecal contamination in water. In areas of intensive livestock activities, such as Brittany, the purpose is mainly to distinguish between human sources and animal sources, namely bovine and porcine as bovine and porcine breeding are generally the most prevalent livestock activities in these regions. We particularly tested if the source assignment deduced from an analysis of the stanol fingerprints in water affected by a fecal contamination of unknown origin were consistent with the information provided by microbial markers that are thought to be source-specific such as Rum-2-Bac (bovine specific microbial marker), L. amylovorus (porcine specific microbial marker) and HF 183 (human specific microbial marker), as well as other chemical markers like caffeine and TCEP. From this point of view, our study joins the few studies published to date that have intended to compare the different MST methods with each other (Blanch et al., 2006; Ahmed et al., 2007; Gourmelon et al., 2010), which is an essential task for the purpose of building a reliable and efficient MST toolbox for effective management and remediation of water resources.

As regards the test of discrimination between fecal samples of human origin on the one hand and fecal samples of bovine and porcine origin on the other hand, we found that the PCA method based on six stanols was successful as unambiguously separated the three types of feces (Figure 2). Based on our results and given the fact that the discriminatory power of our PCA method is based on a large sample population $(n=88)$, comprising a large variety of storage time conditions and secondary treatment processes (Derrien et al., 2011), we feel that this method would be a suitable tool to discriminate between the three main types of feces that are assumed to predominantly threaten water quality in regions such as Brittany. Our results also successfully showed that this method is capable of correctly identifying the 
stanol signatures, even if the feces are modified during their dilution and further transport by runoff. The fact that the introduction of these samples does not affect the resolving power of the PCA analysis based on six stanols is the true test of the applicability of this method to real polluted waters.

\subsection{Efficiency of the PCA method do identify the fecal origin contamination in river samples.}

All of the river water samples analyzed presented E. coli levels that exceeded the limit value of the inland water guidelines of the European Directive on the management of bathing water quality. The PCA method based on six stanols assigned the fecal contamination of all samples from Glanvez catchment to a porcine source and to a bovine source for all the samples of Daoulas and Pénerf River Basin, except sample W5 from the Pénerf River Basin, which was clearly assigned to a human source (Figure 2). These assignments are consistent with the microbial marker data. There is a clear consistency in the case of the Glanvez catchment between the stanol assignment and the detection of the porcine microbial marker $\mathrm{L}$. amylovorus. The consistency between the assignment made for W5 by the 6 -stanolbased method and the source information provided by the Bacteroidales marker HF 183 is important as this microbial marker was already found to be highly human-specific in the EU (Seurinck et al., 2005; Mieszkin et al., 2009; Gourmelon et al., 2010), USA (Kildare et al., 2007) and Australia (Ahmed et al., 2009). The assignment of the fecal contamination detected in the W5 sample is also consistent with the location of this sample, which came from a sampling point located 20 meters downstream of the discharge pipe of the municipal WWTP in operation on the Pénerf River Basin.

There is also a very high level of consistency in the case of the remaining Pénerf River samples and the three Daoulas River samples, the fecal contamination of which clearly appears to be predominantly of bovine origin. Two important arguments supporting this interpretation are: i) the close grouping of all of these samples in the bovine cluster in the PCA score plot (Figure 2), and ii) the detection, in four out of eight samples, of high concentrations of the bovine specific microbial marker Rum-2-Bac. The host specificity of Rum-2-Bac has already been established (Mieszkin et al., 2010; Gourmelon et al., 2010), and the fact that the microbial results are consistent with the results of the PCA method based on six stanols obtained for these samples may be considered as an a posteriori validation of the capability of the PCA method based on six stanols to reliably detect a fecal contamination of bovine origin in water.

It should be noted, however, that the Rum-2-Bac microbial marker was not detected in all of the bovine-contaminated samples. In fact, three Pénerf samples (W1, W3 and W6) showed no traces of this marker. This might be due to a difference in the sensitivity of the markers in relation with differences in the contamination load. This is consistent with the results previously evidenced by Gourmelon et al. (2010) who could not quantified Rum-2-bac in water samples with low levels of E. coli $(<5 \times 102 \mathrm{CFU} / 100 \mathrm{~mL})$, while the stanols could be quantified in these same samples. It should be pointed out that the evidence provided by the PCA method based on six stanols showing that W1, W3 and W6 samples are affected by a diffuse contamination of bovine origin is fully consistent with the agricultural context of this basin. As already noted, Pénerf Basin is the site of intensive dairy farming activities, with a massive return of manure and cowpats to the soil, particularly in lowland cattle pastures. Further studies on the Pénerf River Basin should be necessary to verify the source assignment of these three points at different period of time of the year (dry or wet season). Nevertheless, the PCA method would seem to be particularly welcome in the case of bodies of waters that are only moderately contaminated in the case of bovine-contaminated samples. 


\subsection{Implication in MST studies}

The results of this study have shown the efficiency of the PCA method to identify the fecal contamination of river samples collected in contrasted areas with a clear influence from animal or human origin. Nevertheless, the samples collected did not allow to study together the three main types of fecal contamination described above (i.e. porcine, bovine and human) in the same catchment. The approach developed in this study needs to be performed in this type of context in order to test its robustness. Further studies should also be performed in different regions, climates and geological context before validating the PCA method as a global method to discriminate the sources of fecal contamination.

\section{Conclusion}

This study tested whether or not the PCA method based on six stanols, set up earlier by Derrien et al. (2011) to distinguish between bovine from porcine feces, could suitable for tracking fecal contamination sources in water from areas of intensive agriculture where the contamination context is often marked by the co-existence of human, bovine and porcine fecal contamination sources. Overall, the different tests conducted for this purpose proved to be positive. In particular, a good consistency was observed between the source assignment made by the PCA method based on six stanols and the assignments made by the specific microbial markers. The results of this study are a first step in the validation of this PCA method to identify the sources of fecal contamination.

\section{Acknowledgment}

This study was funded by the ANSES (Agence Nationale de Sécurité Sanitaire, France) through the "TRACES" project (EST-2006/1/36). The CNRS and Région Bretagne are greatly acknowledged for the grant provided to Morgane Derrien to enable her to carry out this study. We thank C. Treguier (Ifremer, La Trinité) and G. Moguedet (Université d'Angers) for their assistance during field sampling and $\mathrm{H}$. Féon and L. Monnier for their analytical support. Dr. S. Mullin post-edited the English style of this paper.

\section{References}

Ahmed, W., Stewart, J., Gardner, T., Powell, D., Brooks, P., Sullivan, D., Tindale, N. (2007) Sourcing faecal pollution: A combination of library-dependent and library-independent methods to identify human faecal pollution in non-sewered catchments. Water Research 41 (16), 3771-3779.

Ahmed, W., Goonetilleke, A., Gardner, T., Powell, D. (2009) Evaluation of multiple sewageassociated Bacteroides PCR markers for sewage pollution tracking. Water Research 43 (19), $4872-4877$.

Asperen, I.A., Medema, G., Borgdorff, M.W., Sprenger, M.J.C., Havelaar, A. H. (1998) Risk of gastroenteritis among triathletes in relation to faecal pollution of fresh waters. International Journal of Epidemiology 27(2), 309-315.

Bernhard, A.E., Field, K.G., (2000). A PCR assay to discriminate human and ruminant feces on the basis of host differences in Bacteroides-Prevotella genes encoding 16S rRNA. Applied and Environmental Microbiology 66 (10), 4571-4574.

Blanch, A.R., Belanche-Munoz, L., Bonjoch, X., Ebdon, J.,Gantzer, C., Lucena, F., Ottoson, J., Kourtis, C., Iversen, A.,Kuhn, I., Moce, L., Muniesa, M., Schwartzbrod, J., Skraber, S., 
Papageorgiou, G.T., Taylor, H., Wallis, J., Jofre, J., 2006. Integrated analysis of established and novel microbial and chemical methods for microbial source tracking. Applied and Environmental Microbiology 72 (9), 5915-5926.

Bull, I.D., Lockheart, M.J., Elhmmali, M.M., Roberts, D.J., Evershed, R.P. (2002) The origin of faeces by means of biomarker detection. Environment International 27(8), 647-654.

Cimenti, M., Hubberstey, A., Bewtra, J.K., Biswas, N. (2007) Alternative methods in tracking sources of microbial contamination in waters. Water SA. 33(2), 183-194.

Derrien, M., Jardé, E., Gruau, G., Pierson-Wickmann, A.C. (2011) Extreme variability of steroids profils in cow faeces and pig slurries at regional scale: implications for the use of steroids to specify faecal pollution sources in waters. Journal of Agricultural and Food and Chemistry 59(13), 7294-7302.

Fattore, E., Benfenati E., Marelli, R., Cools, E., Fanelli R. (1996) Sterols in sediment samples from Venice lagon, Italy. Chemosphere 33(12), 2383-2393.

Field, K.G., Samadpour, M., 2007. Fecal source tracking, the indicator paradigm, and managing water quality. Water Research 41 (16), 3517-3538.

Figuet, C., Frangi, J.P. (2000) Receiving fresh water from domestic wastewater treatment plant outlet: a case study for Mauldre (lle de France), a medium under very high pressure. Revue des Sciences de l'Eau, 13 (2), 119-139.

Gourmelon, M., Caprais, M.P., Mieskin, S., Marti, R., Wéry, N., Jardé, E., Derrien, M., JadasHécart, A., Communal, P.Y., Jaffrezic, A., Pourcher, A.M. (2010) Development of microbial and chemical MST tools to identify the origin of the faecal pollution in bathing and shellfish harvesting waters in France. Water Research 44(16), 4812-4824.

Grimalt, J.O., Fernandez, P., Bayona, J.M., Albaiges, J. (1990) Assessment of fecal sterols and ketones as indicators of urban sewage inputs to coastal waters. Environmental Science and Technology 24(3), 357-363.

Jaffrézic, A., Jardé, E., Pourcher, E., Gourmelon, M., Caprais, M.P., Heddadj, D., Cottinet, P., Bilal, M., Derrien, M., Marti, R., Mieszkin, S. (2011) Microbial and chemical markers: runoff transfer in animal manure-amended soils. Journal of Environmental Quality 40(3), 959968.

Jardé, E., Gruau, G., Mansuy-Huault, L., Peu, P., Martinez, J. (2007a) Using sterols to detect pig slurry contribution to soil organic matter. Water, Air and Soil Pollution 178(1-4), 169178.

Jardé, E., Gruau, G., Mansuy-Huault, L. (2007b) Detection of manure-derived organic compounds in rivers draining agricultural areas of intensive manure spreading. Applied Geochemistry 22(8), 1814-1824.

Jeanneau, L., Jardé, E., Gruau, G. (2011) Influence of salinity and natural organic matter on the solid phase extraction of sterols and stanols: Application to the determination of the human sterol fingerprint in aqueous matrices. Journal of Chromatography A 1218(18), 25132520.

Jeanneau, L., Solecki, O., Communal, P.Y., Jadas-Hécart, A., Gourmelon, M., Caprais, M.P., Wéry, N., Jardé, E., Gruau, G., Pourcher, A.M. (2012) Relative decay of fecal indicator bacteria and human-specific markers: a microcosm study simulating wastewater input into seawater and fresh water. Environmental Science and Technology, 46, 4, 2375-2382.

Kildare, B.J., Leutenegger, C.M., McSwain, B.S., Bambic, D.G., Rajal, V., Wuertz, S. (2007) $16 S$ rRNA-based assays for quantitative detection of universal, human-, cow-, and dogspecific faecal Bacteroidales: a Bayesian approach. Water Research 41 (16), 3701-3715. Leeming, R., Ball, A., Ashbolt, N., Nichols, P.D. (1996) Using faecal sterols from humans and animals to distinguish faecal pollution in receiving waters. Water Research 30(12), 28932900.

Marti, R., Dabert, P., Ziebal, C., Pourcher A.M. (2010) Evaluation of Lactobacillus sobrius/L·amylovorus as a new microbial marker of pig manure. Applied and Environmental Microbiology 76(5), 1456-1461. 
Mieszkin, S., Furet, J.P., Corthier, G., Gourmelon, M. (2009) Estimation of pig fecal contamination in a river catchment by Real-Time PCR using two pig-specific Bacteroidales 16S rRNA genetic markers. Applied Environmental Microbiology 75(10), 3045-3054.

Mieszkin, S., Yala, J. F., Joubrel, R., Gourmelon, M. (2010). Phylogenetic analysis of Bacteroidales 16S rRNA gene sequences from human and animal effluents and assessment of ruminant faecal pollution by real-time PCR. Journal of Applied Microbiology 108(3), 974984.

Scott, T.M., Rose, J.B., Jenkins, T.M., Farrah, S.R., Lukasik, J. (2002) Microbial source tracking: current methodology and future directions. Applied and Environmental Microbiology 68(12), 5796-5803.

Seurinck S., Defoirdt T., Verstraete W., Siciliano S.D. (2005) Detection and quantification of the human-specific HF183 Bacteroides 16S rRNA genetic marker with real-time PCR for assessment of human faecal pollution in freshwater. Environmental Microbiology 7(2), 249259.

Shah, V.G., Dunstan, R.H., Geary, P.M., Coombes, P., Roberts, T.K., Von Nagy-Felsobuki, E. (2007) Evaluating potential applications of faecal sterols in distinguishing sources of faecal contamination from mixed faecal samples. Water Research 41(16), 3691-3700.

Simpson, J.M., Santo Domingo, J.W., Reasoner, D.J. (2002) Microbial source tracking: state of the science. Environmental Science and Technology 36(24), 5279-5288.

Sinton, L.W., Finlay, R.K., Hannah, D.J. (1998) Distinguishing human from animal faecal contamination in water: a review. New Zealand Journal of Marine and Freshwater Research 32 (2), 323-348.

Solecki, O., Jeanneau, L., Jardé, E., Gourmelon, M., Marin, C., Pourcher, A.M. (2011) Persistence of microbial and chemical pig manure markers as compared to faecal indicator bacteria survival in freshwater and seawater microcosms. Water Research 45(15), 46234633.

Tyagi P., Edwards D.R. (2009) Distinguishing between human and animal sources of fecal pollution in waters: a review. International Journal of Water 5 (1), 15-34.

Ufnar, J.A., Ufnar, D.F., Wang, S.Y., Ellender, R.D., 2007. Development of a swine-specific fecal pollution marker based on host differences in methanogen mcrA genes. Applied and Environmental Microbiology 73 (16), 5209-5217. 
Table 1. Table of the chemical and microbial fecal markers used in this study and their source assignment.

\begin{tabular}{|c|c|c|c|}
\hline & Type & Marker & Assignment \\
\hline \multirow{2}{*}{ 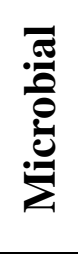 } & $\begin{array}{l}\text { Dominant bacteria of } \\
\text { intestinal tractus }\end{array}$ & L. amylovorus & Porcine \\
\hline & Bacteroidales & $\begin{array}{c}\text { HF183 } \\
\text { Rum-2-Bac }\end{array}$ & $\begin{array}{l}\text { Human } \\
\text { Bovine }\end{array}$ \\
\hline \multirow{2}{*}{ 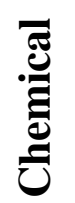 } & Indirect & $\begin{array}{l}\text { Caffeine } \\
\text { TCEP }\end{array}$ & $\begin{array}{l}\text { Human } \\
\text { Human }\end{array}$ \\
\hline & Direct & Stanols & Human, Bovine, Porcine \\
\hline
\end{tabular}


Table 2. Comparison between the concentrations of the fecal microbial and chemical indicators in the river water samples and the contamination source assigned by the PCA analysis of the stanol distributions.

\begin{tabular}{|c|c|c|c|c|c|c|c|}
\hline \multirow[b]{2}{*}{ Samples } & \multirow[b]{2}{*}{$\begin{array}{c}\text { E. Coli } \\
(\mathrm{CFU} / 100 \mathrm{~mL})\end{array}$} & \multicolumn{3}{|c|}{ Microbial markers } & \multicolumn{3}{|c|}{ Chemical markers } \\
\hline & & $\begin{array}{c}\text { L. } \mathbf{a m y}^{\mathbf{1}} \\
(\mathrm{CFU} / 100 \mathrm{~mL})\end{array}$ & $\begin{array}{c}\mathbf{H F 1 8 3}^{\mathbf{2}} \\
\text { (copies/100mL) }\end{array}$ & $\begin{array}{c}\mathbf{R u m}_{\mathbf{2}} \mathbf{2}-\mathbf{B a c}^{\mathbf{3}} \\
(\text { copies } / 100 \mathrm{~mL})\end{array}$ & $\begin{array}{c}\text { Caffeine }^{2} \\
(\mu \mathrm{g} / \mathrm{L})\end{array}$ & $\begin{array}{c}\mathbf{T C E P}^{\mathbf{2}} \\
(\mu \mathrm{g} / \mathrm{L})\end{array}$ & $\begin{array}{l}\text { Source assigned } \\
\text { by stanols }\end{array}$ \\
\hline $\mathrm{C} 1$ & $1.9 \times 10^{4}$ & $\mathrm{bql}^{\mathrm{a}}$ & bql & $3.6 \times 10^{5}$ & bql & bql & Cow \\
\hline $\mathrm{C} 2$ & $1.5 \times 10^{4}$ & bql & bql & $3.0 \times 10^{5}$ & bql & bql & Cow \\
\hline $\mathrm{C} 3$ & $1.7 \times 10^{4}$ & bql & bql & $5.9 \times 10^{5}$ & bql & bql & Cow \\
\hline $\mathrm{P} 1$ & $3.4 \times 10^{3}$ & $3.0 \times 10^{6}$ & bql & bql & bql & bql & Porcine \\
\hline $\mathrm{P} 2$ & $9.2 \times 10^{3}$ & $2.6 \times 10^{6}$ & bql & bql & bql & bql & Porcine \\
\hline P3 & $2.0 \times 10^{3}$ & $1.6 \times 10^{6}$ & bql & bql & bql & bql & Porcine \\
\hline $\mathrm{P} 4$ & $9.7 \times 10^{2}$ & $9.6 \times 10^{5}$ & bql & bql & bql & bql & Porcine \\
\hline P5 & $3.3 \times 10^{2}$ & $4.3 \times 10^{4}$ & bql & bql & bql & bql & Porcine \\
\hline W1 & $1.9 \times 10^{3}$ & bql & bql & bql & bql & bql & Cow \\
\hline W2 & $6.1 \times 10^{3}$ & bql & bql & $1.7 \times 10^{5}$ & 0.09 & bql & Cow \\
\hline W3 & $2.2 \times 10^{3}$ & bql & bql & bql & 0.18 & bql & Cow \\
\hline W4 & $1.4 \times 10^{3}$ & bql & bql & bql & 0.22 & bql & Cow \\
\hline W5 & $1.4 \times 10^{5}$ & bql & $7.3 \times 10^{5}$ & bql & 12.40 & 0.29 & Human \\
\hline W6 & $3.2 \times 10^{3}$ & bql & bql & bql & 0.08 & 0.05 & Cow \\
\hline
\end{tabular}

${ }^{a}$ Below quantification limit. Quantification limit were $<1 \times 10^{3}$ gene copies or cells $/ 100 \mathrm{~mL}$ for bacterial markers and $<0.04 \mu \mathrm{g} . \mathrm{L}^{-1}$ for caffeine and TCEP.

${ }^{1}$ Pig specific marker

${ }^{2}$ Human specific marker.

${ }^{3}$ Ruminant specific marker. 
Table A.1. Eigenvector, factorial coordinates of the variables and relative contributions (in $\%$ ) of variables to principal components $1(\mathrm{~F} 1)$ and $2(\mathrm{~F} 2)$ of the principal component analysis carried out with the runoff samples used as supplementary individuals.

\begin{tabular}{lcccccc} 
& \multicolumn{2}{c}{$\begin{array}{c}\text { Eigenvector } \\
\text { coordinates }\end{array}$} & \multicolumn{2}{c}{$\begin{array}{c}\text { Factorial coordinates } \\
\text { variables }\end{array}$} & \multicolumn{2}{c}{$\begin{array}{c}\text { Contributions of } \\
\text { variables (\%) }\end{array}$} \\
\cline { 2 - 7 } & F1 & F2 & F1 & F2 & F1 & F2 \\
\hline Coprostanol & 0.51 & -0.07 & 0.95 & -0.07 & 25.6 & 0.4 \\
Epicoprostanol & -0.34 & 0.49 & -0.65 & 0.51 & 11.9 & 24.0 \\
Campestanol & -0.38 & 0.52 & -0.72 & 0.54 & 14.5 & 26.9 \\
Sitostanol & -0.43 & -0.24 & -0.80 & -0.25 & 18.1 & 5.9 \\
24-Ethylcoprostanol & 0.27 & 0.59 & 0.51 & 0.61 & 7.2 & 34.4 \\
24-Ethylepicoprostanol & -0.48 & -0.29 & -0.90 & -0.30 & 22.8 & 8.3 \\
\hline
\end{tabular}


Table A.2. Eigenvector, factorial coordinates of the variables and relative contributions (in $\%$ ) of variables to principal components $1(\mathrm{~F} 1)$ and $2(\mathrm{~F} 2)$ of the principal component analysis carried out with all the source samples used as individuals.

\begin{tabular}{lcccccc} 
& \multicolumn{2}{c}{$\begin{array}{c}\text { Eigenvector } \\
\text { coordinates }\end{array}$} & \multicolumn{2}{c}{$\begin{array}{c}\text { Factorial coordinates } \\
\text { variables }\end{array}$} & \multicolumn{2}{c}{$\begin{array}{c}\text { Contributions of } \\
\text { variables (\%) }\end{array}$} \\
\cline { 2 - 7 } & $\mathrm{F} 1$ & $\mathrm{~F} 2$ & $\mathrm{~F} 1$ & $\mathrm{~F} 2$ & $\mathrm{~F} 1$ & $\mathrm{~F} 2$ \\
\hline Coprostanol & 0.50 & -0.07 & 0.96 & -0.07 & 24.7 & 0.5 \\
Epicoprostanol & -0.35 & 0.57 & -0.67 & 0.56 & 12.0 & 31.9 \\
Campestanol & -0.40 & 0.47 & -0.76 & 0.47 & 15.6 & 21.9 \\
Sitostanol & -0.42 & -0.29 & -0.81 & -0.29 & 17.8 & 8.3 \\
24-Ethylcoprostanol & 0.30 & 0.53 & 0.57 & 0.53 & 8.7 & 28.2 \\
24-Ethylepicoprostanol & -0.46 & -0.30 & -0.88 & -0.30 & 21.1 & 9.2 \\
\hline
\end{tabular}


Figure 1. Plot of the principal component analysis of the 88 samples analyzed using the 6 most discriminant stanol compounds proposed by Derrien et al. (2011). Runoff and diluted samples were used as supplementary individuals. F1 axis: principal component 1; F2 axis: principal component 2.

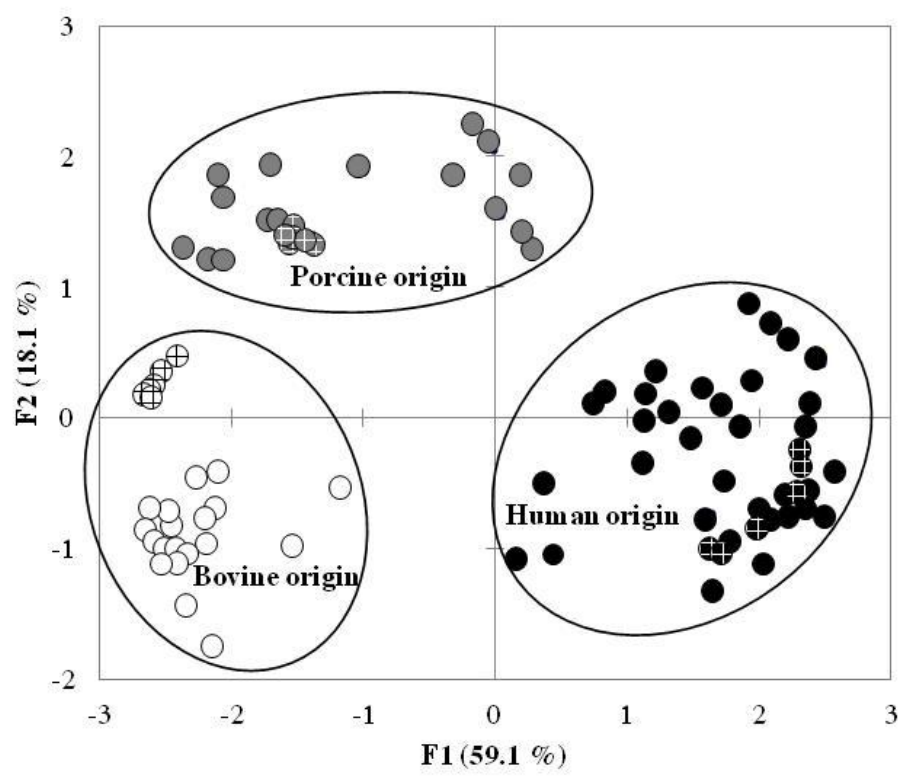

\begin{tabular}{|cc|}
\hline Bovine manures & Porcine manures \\
$\begin{array}{l}\text { Runoff samples } \\
\text { (cow manures) }\end{array}$ & $\begin{array}{l}\text { Runoff samples } \\
\text { (pig manures) }\end{array}$
\end{tabular}


Figure 2. Plot of the principal component analysis comparing the 88 source samples and the 13 river water samples using the 6 most discriminant stanol compounds proposed by Derrien et al. (2011). All of the source samples (i.e. manure, WWTP, runoff and diluted samples) were used as individuals, in contrast to the river water samples which were used as supplementary individuals. F1 axis: principal component 1; F2 axis: principal component 2.

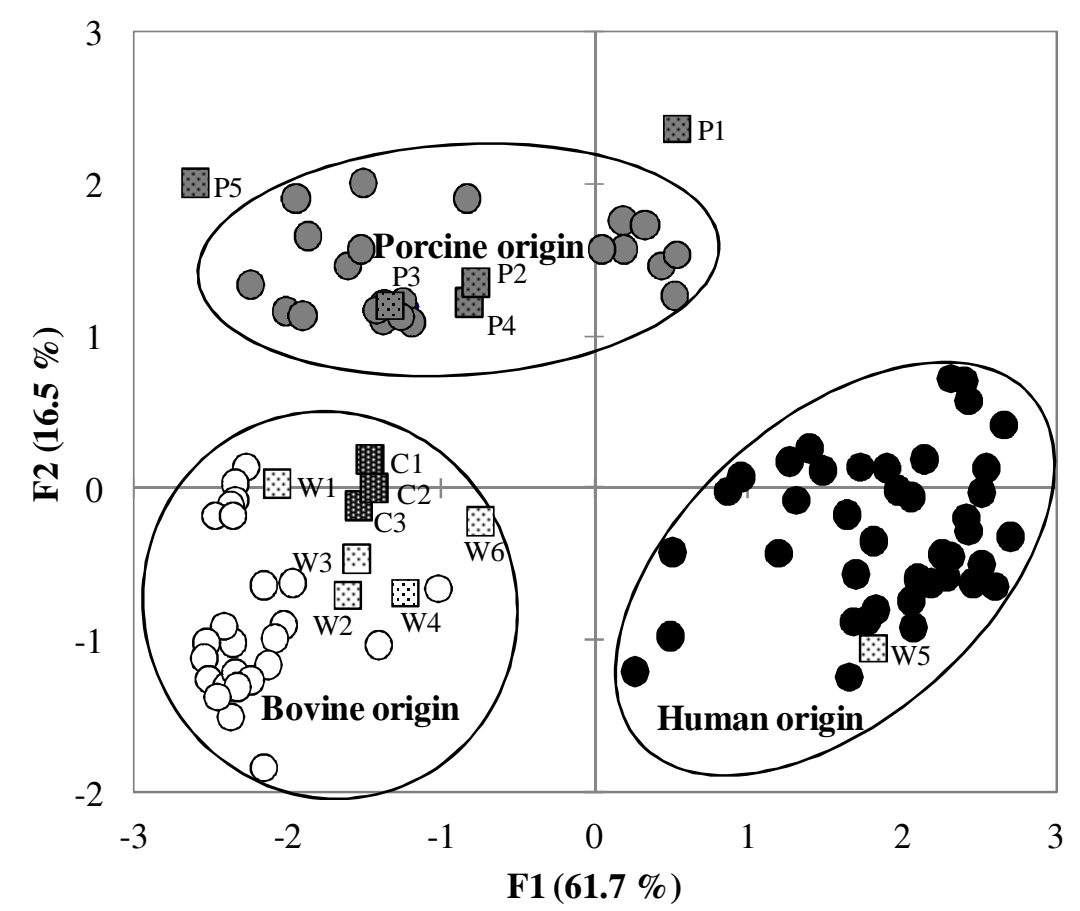

\begin{tabular}{|c|c|c|}
\hline "Source" samples: & $\begin{array}{l}\text { Bovine } \\
\text { Porcine } \\
\text { Human }\end{array}$ & 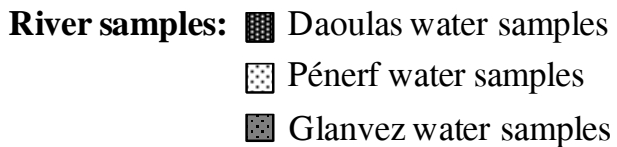 \\
\hline
\end{tabular}

